\title{
Long term follow up of bone derived hydroxyapatite orbital implants
}

\author{
A J Suter, A C B Molteno,T H Bevin, J D Fulton, P Herbison
}

Br J Ophthalmol 2002;86:1287-1292

See end of article for authors' affiliations

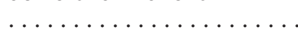

Correspondence to: Professor A C B Molteno, Department of Ophthalmology, University of Otago Medical School, PO Box 913, Dunedin, New Zealand; georgi.bond@ healthotago.co.nz

Accepted for publication 15 February 2002

\begin{abstract}
Aims: To document the long term experience of bone derived hydroxyapatite orbital implants and compare results using scleral wrapped implants with those not using sclera.

Methods: This retrospective case series reviewed the long term follow up of 118 patients with 120 eyes which had undergone enucleation and bone derived hydroxyapatite orbital implant insertion at Dunedin Hospital from 1977 until 2000. Patient details were obtained from theatre records, case note review, patient interview and examination, interview of patient relatives, and family general practitioner records.

Results: Of the 120 eyes 84 had bone derived hydroxyapatite orbital implants with sclera and 36 without sclera. Follow up was $0.5-25$ years (mean 8.9 years). 25 (19.3\%) suffered minor complications of limited exposure of the implant which resolved spontaneously, with implant drilling or wound resuture. Nine $(7.5 \%)$ suffered major complications requiring explantation. Major complications were more likely in cases with major tissue disruption, ischaemia, or inflammation. There were significantly fewer complications in the group where a bone derived hydroxyapatite orbital implant was implanted without a scleral covering $(p<0.05)$.

Conclusions: The placement of a bone derived hydroxyapatite orbital implant in the socket was associated with a low rate of long term complications and good cosmesis in most cases. The omission of a scleral covering over the hydroxyapatite sphere had some advantages and may prove to be the procedure of choice.
\end{abstract}

$\mathrm{T}$ he cosmetic results of simple enucleation are frequently poor with the prosthesis giving an immobile staring appearance and tending to cause sagging of the lower lids and production of a deep hollow below the brow. This outcome can be considerably improved by replacing the lost eye with an orbital implant. The first orbital implants developed by Mules in $1885,{ }^{1}$ were hollow glass, gold, or silver spheres implanted in Tenon's capsule and covered by a layer of extraocular muscle and Tenon's tissue. This allowed a thinner and lighter prosthesis to be used which gave a more natural appearance with better movement. However, Mules's spheres were subject to the late complications of either migration out of the muscle cone or migration forward through the overlying tissues. These complications led to trials of a wide variety of different implant materials including the mineral matrix of cancellous bone (of bovine origin) introduced by Schmidt. ${ }^{2}$ Schmidt implants were prepared by heating spheres of cancellous bone to destroy all organic matter, leaving only the calcium phosphate mineral framework. ${ }^{3}$ (This material was subsequently shown to consist predominantly of ultramicroscopic crystals of hydroxyapatite with smaller, and variable, amounts of calcium carbonate and calcium citrate. ${ }^{4-6}$ ) Schmidt inserted the first implant in 1899 and reported the follow up of this and subsequent cases at regular intervals until 1930. ${ }^{237}$ Schmidt's bone derived hydroxyapatite spheres were recommended by Aust and Guist who reported the results of 30 cases in $1926 .{ }^{8}$ Guist's name became attached to these "calcined" bone spheres which were widely used and recommended as "the most satisfactory of all implants" in Spaeth's The Principles and Practice of Ophthalmic Surgery. ${ }^{9-11}$

After the second world war biologically inert plastic materials displaced the earlier types of implant. Broadly, two types of implant were used, one a monolithic smooth surfaced implant was subject to the complications of late migration and extrusion, while the second type of porous implant, once organised by the tissues, did not tend to migrate but had the disadvan- tage that any exposure of the underlying implant was difficult or impossible to treat without removal of the entire implant. ${ }^{12}{ }^{13}$

The disadvantages of the synthetic plastic implants led one of us (ACBM) to review the literature on orbital implants and note that the earlier bone derived hydroxyapatite implants had given good results and that small exposures of the implant during the postoperative period frequently healed spontaneously. ${ }^{2-10}$ This behaviour, which was quite unlike that observed with a monolithic smooth surfaced or porous plastic implant suggested that the biodegradable microcrystalline hydroxyapatite matrix of bone would form a superior orbital implant since, once organised by host connective tissue, it would not migrate through the tissues while any small exposures would heal spontaneously. Furthermore, the mass of host connective tissue incorporating the bone mineral implant would be likely to persist unchanged for the rest of the patient's life. ${ }^{14}$

The initial trial of this type of implant used antigen free bone as a buried "Iowa" type implant and confirmed that the mineral matrix of cancellous bone was readily incorporated into the tissues and that small exposures were followed by spontaneous crumbling of the exposed bone with healing of the overlying conjunctiva. ${ }^{15}$ This self healing behaviour suggested that larger orbital implants could be inserted with safety and led to trials of large spherical implants which completely filled the socket and supported the eyelids in a natural closed position to eliminate dead space and provide near normal tear distribution and drainage without the presence of a prosthesis. ${ }^{16}$ As the appearance was that of unilateral ptosis instead of a hollow socket patients could remove the prosthesis to rest the conjunctiva and still retain a relatively good appearance when at home or sleeping. During the day patients wore a prosthesis based on a haptic contact lens that moved well and gave a very good cosmetic appearance while maintaining a healthy "self cleaning" socket. The results of 
Table 1 Duration of follow up and indications for enucleation in groups with and without scleral cap

\begin{tabular}{llll}
\hline & $\begin{array}{l}\text { Implant with sclera } \\
(\mathrm{n}=84)\end{array}$ & $\begin{array}{l}\text { Implant without } \\
\text { sclera }(\mathrm{n}=36)\end{array}$ & Total $(\mathrm{n}=120)$ \\
\hline Follow up range (mean) in years & $0.5-23(9.36)$ & $0.5-25(7.56)$ & $0.5-25(8.90)$ \\
Trauma & $41(49 \%)$ & $15(42 \%)$ & $55(46 \%)$ \\
Neovascular glaucoma & $12(14 \%)$ & $8(22 \%)$ & $20(17 \%)$ \\
Primary open angle glaucoma & $2(2 \%)$ & $1(3 \%)$ & $3(3 \%)$ \\
Other glaucoma & $6(7 \%)$ & $1(3 \%)$ & $7(6 \%)$ \\
Tumour & $8(10 \%)$ & $7(19 \%)$ & $15(13 \%)$ \\
Infection & $4(5 \%)$ & $1(3 \%)$ & $5(4 \%)$ \\
Phthysis & $4(5 \%)$ & 0 & $4(3 \%)$ \\
Uveitis & $5(6 \%)$ & $2(6 \%)$ & $7(6 \%)$ \\
Coats' disease & $2(2 \%)$ & $1(3 \%)$ & $3(3 \%)$ \\
\hline
\end{tabular}

this approach were encouraging and 52 cases with up to 10 years of follow up from Dunedin Hospital were reported in 1991. ${ }^{17}$ This communication extends that series and reports the long term outcome of 120 bone derived hydroxyapatite orbital implants inserted after enucleation between 1977 and 2000 .

\section{PATIENTS AND METHODS}

\section{Patient selection}

All patients who had an enucleation with insertion of a bone derived hydroxyapatite orbital implant at Dunedin Hospital between 1977 and 2000 were identified from theatre records. Consent for data retrieval was obtained from the ethics committee of the regional health authority.

\section{Data collection}

The ophthalmology department clinical records were reviewed and surviving patients whose follow up was incomplete were traced through the National Master Patient Index, voters' roll, or the State Accident Insurance Corporation. Patients were telephoned and a structured interview carried out to determine their current status. Where possible patients were seen at an outpatient appointment or examined by colleagues in other centres. For the 20 deceased, the date of death and as much pertinent information as possible were obtained from case notes, relatives, or the family doctor. Adequate follow up was obtained on 120 of the 128 cases identified from theatre records and these form this series. Clinical appearances were documented by photography and cases that had been implanted for more than 10 years had plain $x$ rays of their orbit taken. Twelve patients (six in the sclera group and six in the non-sclera group) had two sequential magnetic resonance imaging scans of their orbits at 3 and 6 months after operation.

\section{Surgical technique}

The aim was to provide an orbital implant which would maintain the normal tear flow and drainage of the conjunctival sac and provide a near perfect cosmetic result. The maintenance of normal tear flow and drainage through the conjunctival sac would require a mobile spherical orbital implant covered by normal conjunctival epithelium and matching the size and situation of the normal eye. Such an implant would, however, leave no room for the wearing of a prosthesis which requires a thickness of approximately $3 \mathrm{~mm}$ in order to avoid the appearance of a flat anterior chamber. It was thus necessary to reduce the volume of the implant slightly and place it more posteriorly in the muscle cone.

\section{Enucleation}

In enucleating the eye care was taken to preserve conjunctiva and to display the four rectus muscles and Tenon's space in their correct anatomical association. The operation was begun by incising conjunctiva and Tenon's tissue around the limbus. Each rectus muscle was then isolated and after tying a 4-0 silk suture through the tendon was cut off at the globe. When the four rectus muscles had been secured, the eye was prolapsed and the optic nerve cut, taking care to avoid buttonholing the conjunctiva. After removing the globe the socket was plugged with a gauze swab while the implant was prepared.

Preparation of the implant

Implants prepared from fine textured three dimensionally porous bovine cancellous bone (M-Sphere, Molteno Ophthalmic, Dunedin, New Zealand) were placed in a solution of cephalosporin $500 \mathrm{mg}$ mixed with gentamicin $80 \mathrm{mg}$ in $4 \mathrm{ml}$ of water.

\section{Choice of surgical technique}

The surgical technique used depended on the preferences of the individual surgeons and the availability of donor sclera. Initially most implants were inserted without a scleral covering; however, the establishment of a national eye bank in 1991 led to most cases being covered by sclera until 1997 when its disadvantages were recognised and its use discontinued.

\section{Implant with scleral cap}

A cancellous bone sphere of approximately two thirds of the diameter of the enucleated eye $(18-20 \mathrm{~mm})$ was selected. A hemisphere of either the patient's own sclera or of a glycerin preserved eye bank sclera was then sewn over the anterior half of the implant using several sutures of 5-0 Vicryl tied over the posterior pole of the implant. In order to insert the implant it was necessary to cover it with a short section of rubber tubing cut from a glove finger to provide a smooth surface. After placing the implant in the rubber tube the interior of the Tenon's capsule was opened by exerting traction on the rectus muscle sutures and grasping the cut edges between the rectus muscles with four small artery clips and drawing them forward. The tube covered implant was pushed back into this cavity with its sclera facing forward and held in place by a finger through the rubber tube while the rubber tube was pulled forward off the implant, drawing the tissues forward as it came free and leaving the implant in the posterior portion of Tenon's cavity. The tissues were closed over the implant by suturing the rectus muscles to the cap of donor sclera in the first 11 cases; however, the rectus muscles were sutured together in pairs with 4-0 silk so as to cover the scleral cap in the 73 subsequent cases. The cut edge of Tenon's tissue was closed in a horizontal line using buried mattress sutures of 4-0 silk, taking care to evert the tissue and avoid leaving any gaps. While the conjunctiva was not sutured separately in most cases care was taken to ensure that the cut edges were everted, opposed, and supported by an intact layer of Tenon's tissue. 
Table 2 Influence of sclera on the incidence of complications after insertion of implants

\begin{tabular}{|c|c|c|}
\hline Size of exposure & $\begin{array}{l}\text { Implant with sclera } \\
(\mathrm{n}=84)\end{array}$ & $\begin{array}{l}\text { Implant without } \\
\text { sclera }(n=36)\end{array}$ \\
\hline \multicolumn{3}{|c|}{ Early complications ( $<6$ months postoperatively) } \\
\hline Large & $3(4 \%)$ & $1(3 \%)$ \\
\hline Small & $15(18 \%)$ & $3(8 \%)$ \\
\hline \multicolumn{3}{|c|}{ Late complications (>6 months postoperatively) } \\
\hline Large & $5(6 \%)$ & 0 \\
\hline Small & 7 (8\%) & 0 \\
\hline Total major & $8(10 \%)$ & $1(3 \%)$ \\
\hline Total minor & $22(26 \%)$ & $3(8 \%)$ \\
\hline All complications & $30(36 \%)$ & $4(11 \%)^{*}$ \\
\hline
\end{tabular}

${ }^{*} p<0.05\left(\chi^{2}\right.$ with Yates's correction and matching for length of follow up).

\section{Implant without a scleral cap}

This was identical to that described above except that donor sclera was not used and a slightly larger (18-22 mm) implant was chosen. The tissues were closed by uniting the superior and inferior rectus muscles end to end using non-absorbable sutures of 4-0 silk. The medial and lateral rectus muscle tendons were then sutured to the corresponding sides of the superior and inferior rectus muscles which then formed an uninterrupted sheet of vascularised muscle tissue across the front of the implant. The cut edges of Tenon's tissue were then sutured together in a horizontal line using buried horizontal mattress sutures so as to oppose Tenon's layer and the conjunctiva as described above.

All operations were concluded by placing a folded piece of vaseline gauze beneath the lower lid and pressing it inferiorly and laterally to maintain adequate depth to the inferior and lateral fornices after which the eye was padded using a single pad held in place by adhesive tape. Pressure bandaging and conformers were deliberately not used in order to avoid pressure necrosis of the tissues covering the implant.

\section{Postoperative care}

Postoperative swelling of the tissues was reduced by the administration of a non-steroidal anti-inflammatory agent (diclofenac 25-100 mg) immediately before or during the operation. The paraffin gauze plug was removed on the first or second postoperative day after which patients used topical Chloromycetin (chloramphenicol) twice daily until the socket had completely healed. Fitting of the artificial eye was delayed for at least 6 weeks to allow time for full vascularisation of the implant and donor sclera if used. An alginate impression of the socket was taken and used to form a haptic contact lens, which formed the basis for the prosthesis. Patients were instructed to remove the prosthesis at night to rest their conjunctiva and to lubricate their socket and maintain their prosthesis with the appropriate hard contact lens lubricating, sterilising, and cleaning solutions.

\section{RESULTS}

Patients were aged 1-98 years at surgery (mean 45.7 years). Sixty nine $(57 \%)$ were male and $51(43 \%)$ female. There were 55 (46\%) left and 65 (54\%) right eyes. Follow up duration was 6 months to 25 years (mean 8.9 years). Eighty four cases had the implant covered with a cap of sclera and 36 had no sclera. These two groups did not differ significantly in their age, sex, or indication for surgery (see Table 1).

\section{Postoperative complications}

The postoperative complications in this series involved breakdown of the covering tissues with exposure of the underlying implant which was significantly more common in the group where the implant had been covered by sclera $(p<0.05)$. Major exposure which resulted in removal or replacement of the implant occurred in nine $(7.5 \%)$ cases. Sclera covered implants were used in eight of these nine cases (see Tables 2 and 3).

Large early exposure ( $<6$ months) with removal of implant Four implants, three of which had been covered with sclera, were exposed and removed early in the postoperative period as a result of extreme swelling of the tissues. In two cases enucleation was carried out acutely to treat ruptured globes associated with facial fractures and two followed enucleation for retinoblastoma in infants.

\section{Large late exposure (>6 months) with removal or} replacement of implant

Late exposure of the implant led to removal in five cases, all of which had been covered with sclera. Exposure occurred between 10 months and 6 years after operation and followed a typical course in all cases-development of a small exposure of the anterior part of the implant, which gradually enlarged. In one case removal was followed by the immediate insertion of a second implant; however, in the remaining cases re-implantation was not attempted.

\section{Small early ( $<6$ months) exposures}

Small exposures occurred soon after operation in 18 cases, of which 15 had been covered with sclera. Three cases, in which sclera had not been used, healed promptly after direct suturing of the conjunctiva (two cases) and debridement (one case). Three cases in which sclera had been used developed small areas of exposure 3-6 weeks after operation which healed spontaneously over a period of weeks. The 12 remaining cases which had been covered by sclera were treated surgically. Eight cases healed immediately after the conjunctiva was sutured. One case healed after the conjunctiva broke down and was re-sutured while three cases only healed after the third attempt at repair.

Small late (>6 months) exposures

Seven implants which had all been covered with sclera developed small areas of exposure between 2 and 8 years after

Table 3 Cases with major complications requiring explantation showing presence of scleral cap, cause of enucleation, cause of complication, and time interval between operation and explantation

\begin{tabular}{|c|c|c|c|c|c|}
\hline Age (years) & Sex & Scleral cap & Cause of enucleation & Cause of complication & Interval \\
\hline 40 & $\mathrm{~F}$ & Yes & Trauma & Ischaemia (maxillary artery transection) & 3 weeks \\
\hline 74 & M & Yes & Neovascular glaucoma & Infected, exposed bone & 10 months \\
\hline 43 & $\mathrm{~F}$ & Yes & Trauma & Chronic exposure then infected & 6 years \\
\hline 54 & $\mathrm{~F}$ & Yes & Endophthalmitis & Chronic exposure then infected & 6 years \\
\hline 1 & M & Yes & Retinoblastoma & Chronic exposure then infected & 4 months \\
\hline 67 & $M$ & Yes & Neovascular glaucoma & Chronic exposure then infected & 2.5 years \\
\hline 27 & M & Yes & Trauma & Chronic exposure then infected & 3 years \\
\hline 68 & $\mathrm{~F}$ & Yes & Necrotising granuloma & Local granuloma of socket & 1.3 year \\
\hline 2 & M & No & Retinoblastoma & Chronic exposure then infected & 6 months \\
\hline
\end{tabular}




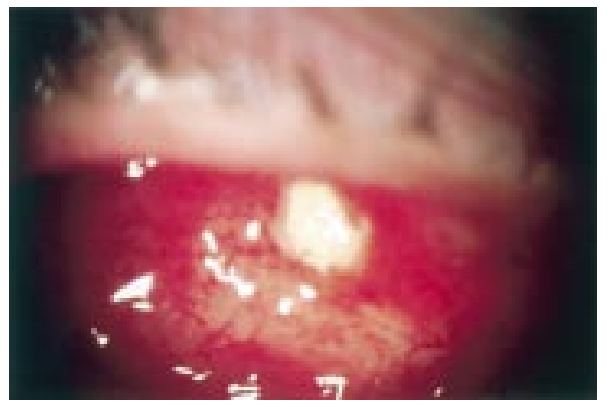

Figure 1 Spontaneous absorption of scleral cap with exposure of underlying non-organised bone 2.5 years after insertion of implant in 32 year old patient $\mathrm{H}$ with diabetes and Turner's syndrome. Photograph shows oedematous conjunctiva with scattered light reflexes and a central area of exposed bone. No treatment was given and the patient continued to wear the prosthesis.

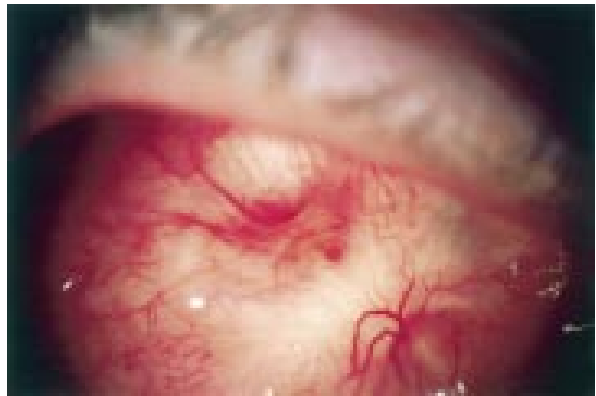

Figure 2 Photograph taken 12 weeks after initial exposure in patient $\mathrm{H}$. The conjunctiva is healthy with few light reflexes Spontaneous debridement of the bone is complete leaving a conical cavity lined by healthy conjunctiva.

operation. These "exposures" were all preceded by spontaneous absorption of the sclera. Slit lamp examination showed healthy Tenon's tissue and conjunctiva closely applied to the organised portions of the implant. In all cases a small centrally placed area showed exposure of non-organised bone. The first three cases were managed by drilling of exposed bone which was followed by healing of the defects. Subsequent cases were treated conservatively. In three of these the exposed bone broke down with spontaneous healing of the defects over periods of 12-120 weeks (see Figs 1 and 2). The remaining case which developed a small area of exposed bone 6 years after operation has remained symptom free and unchanged in size for 5 years before healing spontaneously.

\section{Behaviour of implanted sclera}

In addition to the seven cases mentioned above, one other case showed spontaneous absorption of the sclera, which was first noted 5 years after operation. The conjunctival covering of this implant has remained healthy for the 10 years to the present. Thus there was spontaneous disappearance of the sclera in eight of 84 cases $(9.5 \%)$ including three in which autologous sclera had been used.

\section{Influence of general disease}

Early exposure of the implants was associated with Turner's syndrome in two cases and antiphospholipid 3 microangiopathy in one case. Another patient had tissue breakdown over a sclera covered glass implant after 4 years, a subsequent sclera covered silicone ball which extruded after 3 years, followed by late limited exposure of a subsequent sclera covered implant after 6 years. Finally, one case, in which a necrotising granuloma had destroyed an eye, developed an area of necrotising granuloma in the organised bone implant 1.3 years after enucleation. However, in many cases the patients' poor under-

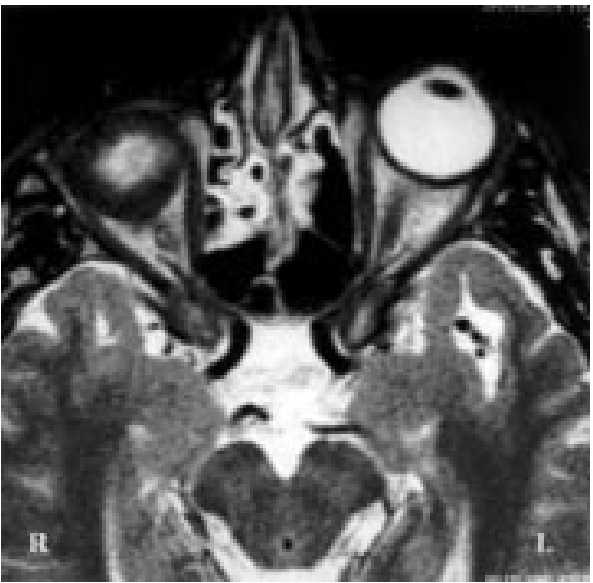

Figure 3 Axial T2 TSE scan (TR $3000 \mathrm{~ms}$ TE eff $120 \mathrm{~ms}$ ) through the mid-orbits in a 60 year old patient 10.5 weeks after enucleation and right implant without a scleral cap. This shows increased T2 signal centrally consistent with oedema here. The presence of oedema indicates the presence of tissue fluid or recent ingrowth of vascular connective tissue while the areas of low signal indicate the presence of mature connective tissue occupying the entire periphery of the implant.

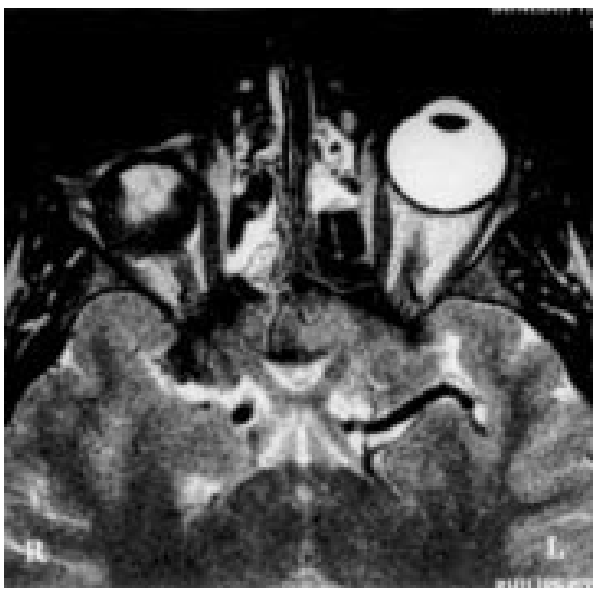

Figure 4 Axial T2 TSE scan (TR $3000 \mathrm{~ms}$ TE eff $120 \mathrm{~ms}$ ) through the orbits of a 19 year old patient 12 weeks after enucleation and right implant with a scleral cap. This shows increased T2 signal consistent with oedema centrally and extending to the anterior surface of the implant, deep to the scleral cover. The presence of oedema indicates the site of tissue fluid or recent ingrowth of vascular connective tissue while the areas of low signal indicate the presence of mature connective tissue occupying the posterior and equatorial periphery of the implant. The scleral cap shows as a linear area of very low signal.

lying condition appeared to have no effect on the behaviour of the implants. For example, a secondary implant was successfully incorporated into the heavily irradiated orbit of a diabetic patient without the use of sclera.

\section{Uncomplicated cases}

In all uncomplicated cases the cancellous bone implants retained their original size and shape for the full duration of follow up, as did the orbital tissues, as evidenced by $x$ rays of the bone implants and the good long term fit of the original prostheses.

\section{Patient satisfaction}

Over $90 \%$ of patients were satisfied with the cosmesis of their implants and prostheses. Many experienced a small amount of discharge which was not troubling. Six patients reported discomfort of the lids in cold weather from the presence of a cold 
Table 4 Exposure outcomes of implants with and without scleral cap per period of follow up

\begin{tabular}{|c|c|c|c|c|c|c|c|c|c|c|}
\hline \multirow[b]{2}{*}{ Outcome } & \multicolumn{5}{|c|}{ Implants with scleral cap } & \multicolumn{5}{|c|}{ Implants without scleral cap } \\
\hline & $\begin{array}{l}0-0.5 \\
\text { years } \\
(n=84)\end{array}$ & $\begin{array}{l}0.5-5 \\
\text { years } \\
(n=82)\end{array}$ & $\begin{array}{l}6-10 \\
\text { years } \\
(n=64)\end{array}$ & $\begin{array}{l}11-15 \\
\text { years } \\
(n=35)\end{array}$ & $\begin{array}{l}16-23 \\
\text { years } \\
(n=15)\end{array}$ & $\begin{array}{l}0-0.5 \\
\text { years } \\
(n=36)\end{array}$ & $\begin{array}{l}0.5-5 \\
\text { years } \\
(n=35)\end{array}$ & $\begin{array}{l}6-10 \\
\text { years } \\
(n=12)\end{array}$ & $\begin{array}{l}11-15 \\
\text { years } \\
(\mathrm{n}=9)\end{array}$ & $\begin{array}{l}16-25 \\
\text { years } \\
(n=7)\end{array}$ \\
\hline Exposure or removal & $3(4 \%)$ & $4(5 \%)$ & $1(2 \%)$ & 0 & 0 & $1(3 \%)$ & 0 & 0 & 0 & 0 \\
\hline Drilled, sutured and healed & $12(14 \%)$ & $3(4 \%)$ & 0 & 0 & 0 & $3(8 \%)$ & 0 & 0 & 0 & 0 \\
\hline $\begin{array}{l}\text { Spontaneous debridement and } \\
\text { healed }\end{array}$ & 0 & $1(1 \%)$ & $2(3 \%)$ & 0 & 0 & 0 & 0 & 0 & 0 & 0 \\
\hline Persisting small exposure & 0 & 0 & $1(2 \%)$ & 0 & 0 & 0 & 0 & 0 & 0 & 0 \\
\hline Spontaneous small healing of sclera & $3(4 \%)$ & 0 & 0 & 0 & 0 & 0 & 0 & 0 & 0 & 0 \\
\hline
\end{tabular}

prosthesis. Movement of the prostheses was good with fine saccadic movement particularly well preserved. No drilling with peg placement was performed. Twenty three (19.2\%) cases required procedures to correct sagging of the lower lid between 4 months and 17 years after surgery.

While about half the patients followed advice on prosthesis care a wide variety of other regimes were used. These included toothbrush and toothpaste, abrasive brass cleaner, and tap water only. Two patients, neither of whom had any problems for the more than 10 years since their surgery, admitted they cleaned and lubricated their prostheses in their mouths. One of these also found that placing his ocular prosthesis in his glass of beer while at the public bar prevented his friends drinking it.

\section{Pattern of organisation}

Magnetic resonance imaging demonstrated that vascular connective tissue invaded the implant at an average rate of approximately $1 \mathrm{~mm}$ per week. In the sclera group ingrowth occurred from the uncovered posterior part of the implant and proceeded towards the anterior pole while in the non-sclera group organisation occurred evenly from the whole circumference of the implant, towards the centre (see Figs 3 and 4).

\section{DISCUSSION}

It is of interest to compare the incidence of complications in this series with those reported after insertion of porous spheres of coral derived hydroxyapatite or polyethylene. The incidence of exposure in these studies varies from 10-28\% with follow up varying from 2 months to 10 years. ${ }^{18-20}$ The variations in the incidence of complications reported can be related to the definition of complications used, the closeness and duration of follow up, the underlying cause for the enucleations, and variations in surgical techniques. The incidence of exposure is lowest when eyes are removed for the treatment of intraocular tumours in adults, with a higher incidence occurring after enucleation for trauma, particularly acute trauma, ocular disease, and tumours in children. A higher incidence is found when larger implants are used. The $29 \%$ exposure rate in the present series with follow up from 6 months to 25 years was made up of $36 \%$ of the cases with scleral cap and $11 \%$ of cases without scleral cap. This series showed that significantly better results were obtained by omitting the use of a scleral cap.

\section{Pathogenesis of complications}

Almost all complications in this series resulted from processes interfering with the organisation of the implants by host tissue. The most important step taken to avoid complications was to maintain an adequate blood supply at all times. This could not always be achieved particularly when eyes were removed acutely as a result of severe trauma. Early massive exposures were associated with marked tissue swelling in the closed orbital cavity which prevented the covering tissues from healing over the implant. In less extreme situations postoperative tissue swelling was adequately dealt with by careful surgical technique and the administration of nonsteroidal anti-inflammatory agents immediately before or during the operation.

Long term maintenance of the conjunctival cover of the implants

The results in this series suggested two conditions necessary for the maintenance of healthy conjunctiva over an implant; firstly, that the anterior portion of the implant be fully organised by vascular host connective tissue and, secondly, that the implant have fine three dimensional pores with delicate bony trabeculae that would rapidly debride to allow spontaneous healing of any small conjunctival defects. The ultrastructure of normal bone consists of bundles of elongated hydroxyapatite crystals intimately associated with bundles of collagen. The hydroxyapatite is responsible for compressive strength while the collagen provides tensile strength. ${ }^{6}$ Removal of the collagen component leaves a structure of bundles of submicroscopic hydroxyapatite crystals held together by weak chemical bonds which are stable in normal connective tissue but break down when exposed to the conjunctival secretions. The spontaneous debridement and healing of non-organised portions of bone exposed by late thinning of scleral caps illustrated this process.

\section{Dystrophic calcification and long term stability of cancellous bone implants}

Dystrophic calcification in old scars occurs by a process in which calcium $\left(\mathrm{Ca}^{2+}\right)$ and phosphate $\left(\mathrm{HPO}_{4}{ }^{2-}\right)$ ions from the tissue fluids combine to form calcium hydrogen phosphate $\left(\mathrm{CaHPO}_{4}\right)$ crystals on collagen fibres which have undergone hyaline degeneration. However, these calcium hydrogen phosphate crystals which are labile and readily reabsorbed back into the tissue fluid undergo a slow spontaneous transformation into hydroxyapatite $\left(\mathrm{Ca}_{3}\left(\mathrm{PO}_{4}\right)_{2}\right)_{3} \cdot \mathrm{Ca}(\mathrm{OH})_{2}$. Hydroxyapatite is a stable crystalline form of calcium phosphate which, under normal conditions, has no tendency to be reabsorbed. ${ }^{21}$ Thus, once hydroxyapatite crystals have formed in connective tissue scars this "dystrophic calcification" usually persists for life. Insertion of the hydroxyapatite mineral matrix of cancellous bone into Tenon's space resulted in the formation of a composite implant of living host connective tissue incorporating the mineral matrix to form a structure corresponding to that present after the occurrence of dystrophic calcification in an old scar.

\section{Heterotopic bone formation}

The fibroblast and osteoblast are closely related cells and heterotopic bone formation occasionally follows dystrophic calcification. It is not known whether this occurred in this series but it seems unlikely that heterotopic bone formation would have any deleterious effect on the long term stability of implants. ${ }^{15} 17$ 


\section{Histological structure of implants}

Six implants were studied histologically at varying periods of less than 10 years after insertion. The uniform findings showed the basophilic amorphous material of the implant organised by moderately vascular dense collagenous connective tissue. No histological evidence of any erosion or decalcification was observed.

\section{Advantages of implantation without sclera}

The increased incidence of complications when sclera was used can be related to the effects of the sclera in preventing tissue from adhering to the implant, preventing full organisation of the implant, and undergoing absorption with late exposure of incompletely organised implants.

\section{Role of sclera in early exposure of implants}

The mechanical effect of covering the implant with a cap of smooth sclera was to prevent the overlying tissues from adhering to the implant. During the first few weeks after operation wound closure depended entirely on sutures placed at the time of operation. The wound broke down in 24 cases $(29 \%)$ in the sclera group which required surgical repair with undermining and resuturing of the tissues, which had to be repeated more than once in four cases. This contrasted with the situation when implants were inserted without sclera when rectus muscles, oblique muscle tendons, and Tenon's tissue adhered firmly to the porous surface of the implant, thereby avoiding tension on the sutures. In the non-sclera group the wound broke down in four cases ( $11 \%)$. In one case the implant was removed while the remaining three cases were successfully repaired by a single intervention.

\section{Role of sclera in preventing full organisation of the implant}

Donor sclera acted as a barrier to direct ingrowth of connective tissue into the anterior portion of the implant. Instead, connective tissue invaded the implant from the posterior portion and grew forward towards the anterior pole. Thus, the anterior part of the implant was the last part to be organised and in some cases failed to organise completely.

\section{Role of sclera in late exposure of implant}

While donor sclera remained unchanged in most cases, in a few cases it underwent late thinning or disappeared entirely. This occurred after insertion of both eye bank and autologous sclera. The effect of late scleral thinning depended on whether or not the implant had been completely organised. Disappearance of donor sclera produced no untoward effects in cases where the implant was completely organised. Late thinning of the sclera over incompletely organised implants caused spontaneous breakdown of the conjunctiva with exposure of the unorganised bone. The spontaneous breakdown and removal of unorganised bone followed by epithelialisation of the defect suggested that fully organised bone should maintain a healthy conjunctiva indefinitely. This strong tendency to self healing behaviour differed markedly from that reported after exposure of coralline hydroxyapatite or porous polyethylene implants. $^{23} 81011$ 18-20

\section{CONCLUSIONS}

This long term series supports the original work of Schmidt ${ }^{237}$ and one of the authors' (ACBM) previous work, ${ }^{15-17}$ which demonstrated that the natural hydroxyapatite mineral matrix of bone could be used to form a large rounded orbital implant which filled the socket, supported the lids, and maintained near normal tear flow and conjunctival physiology when a prosthesis was not worn, and gave a very good cosmetic result when it was. The use of a scleral cap unexpectedly increased the incidence of complications. However, so far, fully organised implants have persisted unchanged without late migration, conjunctival erosion, or shrinkage.

Authors' affiliations

A J Suter, Department of Ophthalmology, Dunedin Hospital, New Zealand

A C B Molteno, T H Bevin, Department of Ophthalmology, University of Otago Medical School, New Zealand

J D Fulton, Department of Radiology, Dunedin Hospital, New Zealand P Herbison, Department of Preventive and Social Medicine, University of Otago Medical School

\section{REFERENCES}

1 Mules PH. Evisceration of the globe, with artificial vitreous. Trans Ophthalmol Soc UK 1885;5:200-6.

2 Schmidt H. Zur Lösung des Problems der Kugeleinheilung. Zeitschrift für Augenheilkunde 1906;16:63-80.

3 Schmidt H. Zur Lösung des Problems der Kugeleinheilung. Nachtrag 1909. Zeitschrift für Augenheilkunde 1910;23:321-39.

4 Klement R, Trömel G. Hydroxylapatit, der Hauptbestandteil der anorganischen Knochen- und Zahnsubstanz. Hoppe-Seyler's Zeitschrift für Physiologische Chemie 1932;230:263-9.

5 Bredig MA. Zur Apatitstruktur der anorganischen Knochen- und Zahnsubstanz. Hoppe-Seyler's Zeitschrift für Physiologische Chemie 1933;260:239-43

6 McLean FC, Urist MR. Bone fundamentals of the physiology of skeletal tissue. 3rd ed. Chicago: University of Chicago Press, 1968.

7 Schmidt, H. Zur kritischen Würdigung der plastischen Stumpfbildungsmethoden. Berlin: Verlag von S Karger, 1930

8 Aust W, Guist G. Zur Stumpfverbesserung nach Enukleation. In: Denk W schriftleiter. Wiener Klinische Wochenschrift. Organ der Gesellschaft der Ärtze in Wien 1926:934.

9 Spaeth EB. The principles and practice of ophthalmic surgery. London: Henry Kimpton, 1939:124

10 Allen TD. Guist's bone spheres. Am J Ophthalmol 1930;13:226.

11 McCoy LL. Guist bone sphere. Am J Ophthalmol 1932;15:960.

12 Pearlman MD. Buried orbital implant. Am J Ophthalmol 1953;36:1756

13 Allen JH, Allen L. A buried muscle cone implant. Arch Ophthalmol 1950;43:879-90.

14 Walter JB, Talbot IC. Walter and Israel general pathology. 7th ed. New York: Churchill Livingstone, 1996:644-7.

15 Molteno ACB, Van Rensberg JHJ, Van Rooyen B, et al. "Physiological" orbital implant. Br J Ophthalmol 1973;57:615-21.

16 Molteno ACB. Antigen-free cancellous bone implants after removal of an eye. Trans Ophthalmol Soc NZ 1980;32:36-9.

17 Molteno ACB, Elder M. Bone implants after enucleation. Aust NZJ Ophthalmol 1991;19:129-36.

18 Buettner H, Bartley GB. Tissue breakdown and exposure associated with orbital hydroxyapatite implants. Am J Ophthalmol 1992;113:669-73

19 Remulla HD, Rubin PAD, Shore JW, et al. Complications of porous spherical orbital implants. Ophthalmology 1995;102:586-93.

20 Lee V, Subak-Sharpe I, Hungerford JL, et al. Exposure of primary orbital implants in postenucleation retinoblastoma patients. Ophthalmology 2000; 107:940-6.

21 Guyton AC, Hall JE. Textbook of medical physiology. 10th ed. Philadelphia: WB Saunders, 2000 